\title{
Psychological factors of impulsive savings traits: survey carried out in Indonesia, Malaysia, Thailand, and Vietnam
}

\author{
Ritzky Karina Brahmana* \\ Faculty of Economics, \\ Universitas Kristen Petra Surabaya, \\ Siwalankerto, 60236, Indonesia \\ Email:karina@peter.petra.ac.id \\ *Corresponding author
}

\section{Rayenda Khresna Brahmana}

Faculty of Economics and Business, Universiti Malaysia Sarawak, Kota Samarahan, 94300, Malaysia Email: brkhresna@feb.unimas.my

\begin{abstract}
This paper attempts to answer an interesting but empirically challenging question: do personality, aggressiveness, and mood lead to changes in savings behaviour? This paper has adopted psychometric tests - UPPS Personality Traits, Aggressiveness (AGGR), and Happiness (POMS) - as the instruments, which were tested in Indonesia, Malaysia, Thailand, and Vietnam (ASEAN-4) by using a survey mode with 2,257 respondents. The results show that an individual with aggressive behaviour tends to have compulsive behaviour in consumption by making fewer savings. The mood of an individual also induces savings behaviour. Interestingly, aggressiveness is the mediator to explain the association between mood and savings behaviour. The personality type also affects spending behaviour. However, this moderating effect of personality was only observed in Thailand and Vietnam, not in Indonesia and Malaysia. Regulators can use the findings by controlling inflation through monetary policy following the mood cycles of individuals. The findings can also be used for policymaking.
\end{abstract}

Keywords: personality; aggressiveness; happy moods; savings behaviour; compulsive behaviour; Indonesia; Malaysia; Thailand; Vietnam.

Reference to this paper should be made as follows: Brahmana, R.K. and Brahmana, R.K. (2016) 'Psychological factors of impulsive savings traits: survey carried out in Indonesia, Malaysia, Thailand, and Vietnam', Int. J. Happiness and Development, Vol. 3, No. 1, pp.1-21.

Biographical notes: Ritzky Karina Brahmana is a Lecturer and currently a Program Secretary for Marketing Department at Faculty of Economics, Universitas Kristen Petra Surabaya. She has a great interest in social marketing, local economics development, digital marketing mood and consumption, and behavioural marketing. She has published several research papers in international journals and conference proceedings, for example, South East Asian Journal of Management, The Asian Journal of Technology Management and more. She also a Peace Building trainer and concern about Service Learning for local economics development of SMEs. 
Rayenda Khresna Brahmana is currently a Senior Lecturer at Faculty of Economics and Business, and also a Research Fellow of Centre of Excellence for Business Economics and Finance Forecasting at Universiti Malaysia Sarawak. He has published several research papers in international journals and conference proceedings, for example, Journal of Bioeconomics, International Journal of Social Economics, Global Business and Economics Review, and many more. He is also associate managing editor for International Journal of Business and Society (IJBS). His current research area is on corporate strategy, experimental economics, and behavioural finance.

This paper is a revised and expanded version of a paper entitled 'Psychological factors of impulse savings traits: survey carried out in Indonesia, Malaysia, Thailand, and Vietnam' presented at The Global Advanced Research Conference on Management and Business Studies, Bandung, Indonesia, 22-24 December 2012.

\section{Introduction}

George had a bad day. He came late to the office in the morning and was reprimanded by his supervisor. The weather was also not too good as the temperature was higher than normal. He became very aggressive and tried to overcome it. Because he is an introvert, he kept his temper inside, and went to a shopping mall for a cup of coffee where he thought he could override his bad day by carrying out that impulsive consumption behaviour.

George performed impulsive consumption behaviour, which is called the reflective-impulsive model by Strack et al. (2006). His mood state made him unconscious (reflective), and his interpersonal trait (impulsive) moderated him to carry out consumption or less savings. In behavioural economics, this type of behaviour is addressed by Kahneman and Tversky (1974) as heuristic bias.

Theories in macroeconomics studies postulate that savings are important for national and individual wealth. For example, there is life-cycle theory stating that country wealth depends on national saving. There is also precautionary savings motives theory stating that savings may induce the future happiness of individual. Even though savings behaviour is important of nation's wealth, not many empirical papers have investigated how psychological variables affect individual's savings behaviour.

To date, economists have mainly focused on the effects of macroeconomic or microeconomic variables on savings behaviour, but not at an individual level. For instance, Ghosh and Ostry (1997) showed that the greater uncertainty in national cash flow and the less government consumption, the greater will be the precautionary savings of that country. Iscan (2011) by using medium run variation in the US savings rate, documented that the slowdown of productivity growth reduced the savings rate and the consumption-income ratio over the period 1980-2000. In terms of the association between microeconomics and savings behaviour, and by using cross-section microanalysis and a time-series macroanalysis, Borsch-Supan and Stahl (1991) discovered how bank savings programs could influence personal savings. If there is research at an individual level, such as Wahhaj (2010), it is more on the role of culture or norms on individual savings. Research that links savings decisions and the psychological point of view is rarely found. 
Interestingly, behavioural economists believe that the utility concept of economic decision has to elaborate with human emotions and affection (see Kahneman et al., 1999).

Recent contributions from behavioural studies have provided strong support for the idea of how emotions play a key role in decision-making. Biel et al. (2011) who found that differences in emotions and moral perceptions can account for part or all of the discrepancy found between the willingness to accept and the willingness to pay. There are also Koenigs and Tranel (2007) and Van Winden et al. (2011) addressed emotions as an important driving factor in investing decision. Brahmana et al. (2012) addressed affection as a source of irrational decision-making. There are also studies linking between emotion and consumption. For example, Stillman et al. (2012) found that higher levels of spirituality are associated with a decreased desire to consume material goods in a conspicuous manner.

Those findings lead to a conclusion that economy irrationality of the individual can be explained by considering the attitude in decision making. Attitudes are not only based on rationality but also on feelings or other hedonic variables (Tvede, 2002). Note that this attitude in decision making has been discussed in psychology studies far earlier than economics findings. Janis and Mann (1977) addressed the issue by proposing emotional state as the driver in biased decision-making. They did a psychology experiment and survey, and found that people tend to change their decision following their mood and emotion. Mann (1992) showed that stress and affection are significantly associated in risk-taking decisions. Others, such as Forgas (1989), Gul and Pesendorfer (2004), and Harle et al. (2012) have similar conclusion where affection, such as sad feelings or aggressiveness, would influence individual decision.

Coming back to the earlier narrated story of George, this research believes that there are many other 'Georges' out there whose decision-making is influenced by their personality traits, aggressiveness characteristics, and mood state. Based on earlier findings and literature about decision making, we hypothesise that:

a mood state has a positive effect on savings decision-making

b there is a moderating effect of impulsive personality traits on the relationship between aggression and savings

c aggressiveness characteristics positively correspond to the savings decision as mediator.

This research aims to answer an interesting but empirically challenging question: Does mood lead to aggressiveness and influence savings behaviour? Do impulsive personality traits moderate that relationship? This research argues that traditional economics is characterised by rational decision-makers maximising a given utility function under constraints. In contrast with that basic tenet of traditional economics, this research proposes the hedonic utility through which decision-making could be based on the moods or character of the individual.

This paper is unique and different from others in three aspects. Firstly, this study utilises psychology to analyse the behaviour of the individual in savings. Secondly, the sample of this study is four ASEAN countries - Indonesia, Malaysia, Thailand, and Vietnam - indicating that a thorough research was conducted by studying the four countries in survey mode. It makes this research give clearer and more general conclusions about the role of psychology on savings decision-making in the South East 
Asia region. Note that these four countries, combined, are leading emerging countries in Asia, and by far, there is rare to find a cross-countries research, especially in developing market context. Thirdly, unlike previous studies, such as Guven (2012) and others, this study carries out a survey study in which the questionnaires were distributed in four countries. Using country-based national surveys in a cross-sectional study would result in a biased result. Furthermore, national surveys would not tally with an individual psychometric result. Lastly, this study not only investigates relationships, but also the mediating and moderating effects.

The remainder of the paper is organised as follows. Section 2 provides an overview of the related literature describing the relationships among the variables. Section 3 addresses the empirical model and the research framework, while Section 4 describes the data used in this research. Section 5 presents an estimation of the statistical result. Lastly, Section 6 and Section 7 present the discussion and the conclusion, respectively.

\section{Related Literature}

\subsection{The role of mood in human behaviour}

The concept of mood and decision-making has been a major research area in psychology for a long time. Studies have shown how mood can be influenced by temperature (Keller et al., 2005), economic pressure (Stein et al., 2012), income inequality (Moutoussis, 2011) or even music (Van der Zwaag et al., 2012). Others have shown how mood influences habit, behaviour, and decision-making. The classic work was Davis et al. (1985) who examined the role of mood on the decision to eat, and showed how having a positive mood would induce the decision to eat as compared to having a negative mood that would reduce the consumption of food. Steptoe and Wardle (1999) documented how alcohol intake was associated with a high positive and low anxious mood. They also documented that drinking coffee and tea are also related to the mood state of the individual. A more recent study was conducted by Harle et al. (2012) who used fMRI in their experiments. After testing the neurons of individuals, they discovered that sad people tend to have aversive emotional states and cognition conflicts and have a tendency to be more sensitive when looking at an unfair situation.

The famous classical work regarding the relationship between mood and economic activity was undertaken by Isen and Simmonds (1978) who found that people tend to do shopping when they feel happy, and, conversely, they tend to do less shopping when they are not in a good mood. Forgas (1989) documented that moods (feeling happy, sad, or neutral) affect strategic decision-making (i.e., cost efficiency). Beja (2012) did a cross-sectional study by examining happy people's choices in economic growth acceleration. Beja's results indicate that happy people tend to choose stable rather than rapid economic growth. In terms of its relationship to savings, Guven (2012) discovered how temperature-induced mood can influence the savings behaviour of the individual. Using the Dutch Household Survey, sunshine played an important role in the decision to save more, spend less, and the lower marginal propensity to consume. 


\subsection{Aggressiveness and decision-making}

Extensive psychology research has shown the important role of aggressiveness in human behaviour. Aggressive people or those with a temperamental personality, for instance, are hastier in making decisions compared to normal or calm individuals. Dodge and Newman (1981) showed how an aggressive boy would have biased decision-making. The biased decision-making and judgement can also be seen in deviant behaviour, such as eating behaviour (Mehrabian and Riccioni, 1986) or the shooting decision of a police officer (Kleider and Parrott, 2009). Carlson et al. (2009) found that aggressive behaviour, if transformed in driving style, would influence the fuel consumption of a car. Moreover, aggressive people tend to take more health risks compared to normal people (Vollrath and Torgersen, 2002).

From an economic perspective, the aggressiveness would affect the utility and become more hedonic (see Caplin and Leahy, 2001). Epstein and Zin (1989) addressed the conceptual framework of the relationship between risk-averse behaviour and temporal consumption. Brandstatter (1993) pointed to differential effects of socio-economic conditions on people's well-being depending on the temperament of their personality. This is reciprocal to Camerer (2011) who argued that emotion could influence people ${ }^{\text {"e }} \mathrm{s}$ economic choices, for instance price, information and income. Tracing back to the classic work in finance, Sandmo (1969) found how risky behaviour was associated with consumption behaviour and portfolio choice. Gul and Pesendorfer (2004) studied the behaviour of individuals towards temptation in consumption. They documented that a lack of dynamic self-control, such as an aggressive person, would probably decrease the equity premium. Indeed, this is in line with Rabin (1998) who showed that if we have self-control we can control our over-consumption, wealth accumulation, savings, and financial behaviour.

\subsection{Impulsive personality, behaviour and intertemporal savings}

The dossiers on the effects of an impulsive personality on judgement and decisionmaking have shown how human choices are moderated more by their personality than driven by their utility optimisation. In optimising their utility through consumption and savings, individuals have different judgements depending on their impulsivity. For instance, Seaver and Patterson (1976) discovered that different impulsive personalities have different levels of fuel consumption. Additionally, Kassarjian (1971) reviewed and addressed how the consumer acts differently towards choices because of their personality characteristics.

Additionally, the relationship between impulsive personality and savings behaviour has also been documented in the economics literature. For instance, Lunt (1991) discovered how the impulsive personality based on the psychological and social demographic variables influences the savings behaviour and recurrent savings behaviour. Frank and Hutchens (1993) found that easy-to-satisfy individuals rely on their satisfaction not only in terms of the level of consumption but also in respect of the rate of change. They also argued that the wage profile of individuals would influence the personal savings rate. A recent study by Harrison and Chudry (2011) provides a deeper insight of personality and its relationship with savings behaviour. They used Eysenck's Personality Traits $^{1}$ and showed how different personalities have different savings 
behaviour. Harrison and Chudry (2011) documented that the tendency of an extrovert to use overdrafts and borrow from family members led to higher anticipated debts on graduation. They also documented that neuroticism was found to not have any significant relationship to borrowing behaviour, but that it was a significant predictor for student anxiety about money management. Other research papers, which used different measurements of personality instead of Eysenck's Personality Traits, also found that personality affects savings behaviour. Donnelly et al. (2012) discovered that individuals who believe that material possessions can provide happiness manage their money less well, and that highly conscientious individuals manage their money better because they have positive financial attitudes as well as a future orientation. They also explained that those characteristics are closely associated with increased savings, decreased debt, and less compulsive buying. Tangari and Smith (2012) argued that individuals who are future-oriented are likely to have more positive savings compared to near-future individuals. Another study, by Shoham and Malul (2012), found how the level of uncertainty avoidance and collectivism has a significant impact on the level of savings. The more collectivist the society, the higher the savings rate. Concisely, the literature has documented how personality takes an important role in the savings behaviour of individuals.

\section{Empirical model and framework}

This research aims to investigate the role of the mediation effect of aggressiveness and the moderating effect with impulsive personality on the relationship between mood and intertemporal savings behaviour (see Figure 1). Firstly, we estimate the function of aggressiveness:

$$
\text { aggressiveness }=f(\text { Mood })
$$

This is followed by its structural relationship towards savings traits. The savings behaviour function can be written as follows:

$$
\text { Savings }=f(\text { Mood }, \text { Aggressiveness, Impulsivity }),
$$

where

$$
\text { Savings } \circ \text { Aggressiveness }
$$

Hence, the function is modified into:

$$
\text { Savings }=f\left\{\begin{array}{l}
\text { Mood }, \text { Aggressiveness, } f(\text { Aggressiveness }), \text { Impulsivity }, \\
\text { Aggressiveness } * \text { Impulsivity }
\end{array}\right\}
$$

The function is estimated by following the Baron and Kenny (1986) steps of moderator-mediator regression model, where the steps are as follows.

We run equation (1) as the first step in examining the role of mood on aggressiveness.

$$
\text { Aggressiveness }=\beta_{0}+\beta_{1} \operatorname{Mood}_{i}+\varepsilon_{i}
$$

The second step is the investigation of the link between the savings traits and aggressiveness. The estimation model is stated in equation model (2): 


$$
\text { Savings }=\beta_{0}+\beta_{1} \text { Aggressiveness }_{i}+\varepsilon_{i}
$$

The third step is estimated by examining the role of impulsivity on the relationship between aggressiveness and savings behaviour. The estimation mode is stated in equation model (3).

$$
\begin{aligned}
\text { Savings } & \beta_{0}+\beta_{1} \text { Aggressiveness }_{i}+\beta_{2} \text { Impulsivity } \\
& +\beta_{3} \text { Aggressiveness } * \text { Impulsivity }_{i}+\varepsilon_{i}
\end{aligned}
$$

Lastly, we estimate the model of the association between moods and the savings traits.

$$
\text { Savings behaviour }=\beta_{0}+\beta_{1} \text { Moods }_{i}+\varepsilon_{i}
$$

Note that the structural equation model under partial least squares is employed to solve the function of savings. Hence, the three-step model of Baron and Kenny (1986) can be skipped and the model shown in Figure 1 [equation (3)] can be run instead.

Figure 1 The research framework

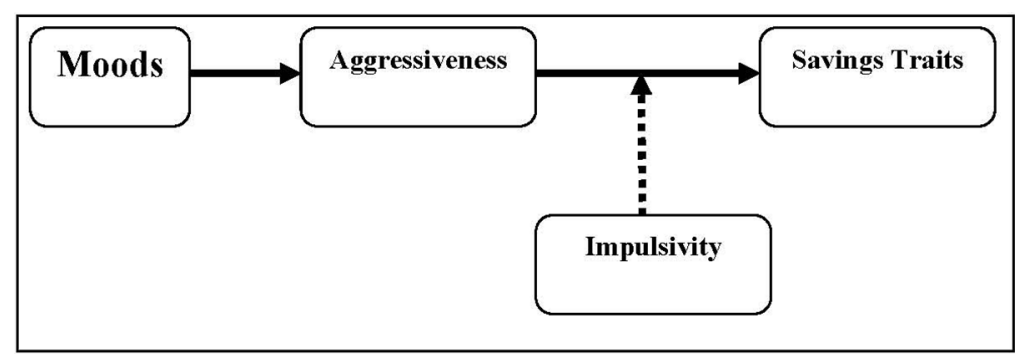

\section{Data}

The data used in this paper were obtained by a survey study. Unlike Guven (2012), the survey was conducted by distributing a questionnaire in four ASEAN countries (Indonesia, Malaysia, Thailand and Vietnam) instead of using the government household survey (GHS). The GHS has several issues, such as

1 not suitable for cross-sectional study

2 different countries have differently-based years and measures

3 not all countries have GHS. ${ }^{2}$

This makes our study more robust compared with others.

We contacted and hired professional field officer in Thailand and Vietnam. Meanwhile, survey in Malaysia and Indonesia were conducted by us. The sampling frame is the local people of each country. This means there is no expatriate or tourist taken as the sample. The sampling method is run under random sampling. Note that the period of data collection was from January 2013 to June 2013. To avoid the non-response bias, we conducted the t-test difference on the first three-month respondents (January 2013-March 2013) and second three-month respondent (April 2013-June 2013). 
The results show there is no significant difference implying there is no issue of non-respondent bias error. The number of respondents can be seen in Table 1.

Table 1 Respondents by country

\begin{tabular}{lccccc}
\hline & Indonesia & Malaysia & Thailand & Vietnam & Total \\
\hline Respondents & 519 & 566 & 595 & 577 & 2,257 \\
\hline
\end{tabular}

The survey consisted of

a savings traits

b mood state

c aggressiveness

d impulsivity traits, and was recorded using a five-point Likert scale.

The savings traits were a modification of the savings traits of Guven (2012), in which we modified and adapted the four items. Following Retiveau et al. (2004), Steinhauser et al. (2011), and Johnson et al. (2012), the mood state was adapted from the Profile of Mood State psychometric tests of Cella et al. (1987). Meanwhile, the aggressiveness was adapted from Buss and Perry (1992) and we used the well-known UPPS Impulsive Behaviour scale for the Impulsivity Trait (see Whiteside and Lynam, 2001). The goodness of measures of the items was tested starting from their reliability, construct validity, convergent validity, and discriminant validity. ${ }^{3}$

\section{Empirical results}

\subsection{Correlation matrix results}

Table 2 presents the correlations among the variables with a mixed value of coefficients. The results show that there are highly correlated variables in each country. A low correlation value is found in the association between impulsivity and moods, and also impulsivity and aggressiveness with less than 0.1 .

Table 2 Correlation matrix results

\begin{tabular}{|c|c|c|c|c|c|c|c|c|}
\hline & \multicolumn{4}{|c|}{ Indonesia } & \multicolumn{4}{|c|}{ Malaysia } \\
\hline & $M$ & $A$ & $I$ & $S$ & $M$ & $A$ & $I$ & $S$ \\
\hline M & 1 & & & & 1 & & & \\
\hline A & 0.441 & 1 & & & 0.407 & 1 & & \\
\hline I & 0.108 & 0.126 & 1 & & 0.097 & 0.118 & 1 & \\
\hline S & 0.498 & -0.399 & 0.103 & 1 & 0.359 & -0.366 & 0.109 & 1 \\
\hline
\end{tabular}

Notes: Mood is denoted as M; aggressiveness is denoted as A; impulsivity is denoted as $\mathrm{I}$; savings traits are denoted as $\mathrm{S}$. 
Table 2 Correlation matrix results (continued)

\begin{tabular}{|c|c|c|c|c|c|c|c|c|}
\hline & \multicolumn{4}{|c|}{ Thailand } & \multicolumn{4}{|c|}{ Vietnam } \\
\hline & $M$ & $A$ & $I$ & $S$ & $M$ & $A$ & $I$ & $S$ \\
\hline M & 1 & & & & 1 & & & \\
\hline A & 0.422 & 1 & & & 0.480 & 1 & & \\
\hline I & 0.113 & 0.098 & 1 & & 0.125 & 0.098 & 1 & \\
\hline $\mathrm{S}$ & 0.372 & -0.477 & 0.363 & 1 & 0.484 & -0.488 & 0.371 & 1 \\
\hline
\end{tabular}

Notes: Mood is denoted as M; aggressiveness is denoted as A; impulsivity is denoted as I; savings traits are denoted as $\mathrm{S}$.

\subsection{Model goodness of fit}

The R-squared values, which are depicted in Table 7, are the proxy for the goodness of fit of a model. The results show that the predictors are good in approximating the real data point where the values are relatively high (higher than 0.1). For instance, the full model of savings behaviour can be explained by its respective predictor of $20.1 \%, 11.5 \%$, $21.6 \%$, and $24.8 \%$ for the model of Indonesia, Malaysia, Thailand, and Vietnam. Meanwhile the aggressiveness model (mediator model) documents a very high R-Squared where the values are $33.3 \%, 44 \%, 41.1 \%$, and $33.4 \%$ for Indonesia, Malaysia, Thailand, and Vietnam, respectively.

Table 3 Findings for moods and savings traits

\begin{tabular}{lc}
\hline & $O L S$ \\
\hline Indonesia & $0.168 * * *$ \\
& $(2.576)$ \\
$\mathrm{n}=519$ \\
\hline Malaysia & $0.144 * *$ \\
& $(2.21)$ \\
\hline Thailand & $\mathrm{n}=566$ \\
\hline $\mathrm{N}$ & $0.256 * *$ \\
\hline Vietnam & $(2.513)$ \\
\hline
\end{tabular}

Notes: The estimate model is run using cross-sectional data. t-value statistics are in parentheses, and above them is the coefficient value. $n$ means the observation of sample. Meanwhile, $\mathrm{N}$ is the total sample from four countries. *, **, and *** denote $10 \%$ significance, $5 \%$ significance, and $1 \%$ significance, respectively. 


\subsection{Mood and savings traits}

Table 3 estimates equation (4) where mood is the predictor for savings traits in four different countries. The coefficients of the models are $0.168,0.144,0.256$, and 0.189 for Indonesia, Malaysia, Thailand, and Vietnam, respectively. The t-values are also higher than 1.960 indicating that the associations are significant at the 5\% level. Therefore, the results imply that mood has a positive effect on the savings traits in those four countries. The better the mood, the stronger the savings. This supports prior research, such as Beja et al. (2012), and Guven (2012), where mood has a significant influence on intertemporal choice.

\subsection{Aggressiveness and savings traits}

The estimations of the association between aggressiveness and savings traits are portrayed in Table 4. The results show that aggressiveness lowers the savings traits with t-values of 2.661, 2.376, 2.770, and 2.601; a value that is higher than $1.96(5 \%$ significance level). Interestingly, the associations are negative between aggressiveness and savings behaviour. Higher values of aggressiveness lead people to make fewer savings. These results are reciprocal to previous research, such as Epstein and Zin (1989), and Gul and Pesendorfer (2004).

Table 4 Findings of aggressiveness and savings traits

\begin{tabular}{lc}
\hline & OLS \\
\hline \multirow{2}{*}{ Indonesia } & -0.407 \\
& $(2.661)$ \\
& $\mathrm{n}=519$ \\
\hline Malaysia & -0.362 \\
& $(2.376)$ \\
Thailand & $\mathrm{n}=566$ \\
\hline & -0.335 \\
& $(2.77)$ \\
\hline & $\mathrm{n}=595$ \\
\hline $\mathrm{N}$ & -0.384 \\
\hline
\end{tabular}

Notes: The estimate model is run using cross-sectional data. t-value statistics are in parentheses, and above them is the coefficient value. $\mathrm{n}$ means the observation of sample. Meanwhile, $\mathrm{N}$ is the total sample from four countries. *,**, and *** denote $10 \%$ significance, $5 \%$ significance, and $1 \%$ significance, respectively. 


\subsection{Mediation of aggressiveness}

Equation (3) estimates the mediation effect of aggressiveness on the relationship between mood and savings traits. It shows a significant association in which aggressiveness mediates the relationship significantly with t-values of $2.784,2.007,2.875$, and 2.566 in Indonesia, Malaysia, Thailand, and Vietnam, respectively. The mediating effects in these countries have a partial mediator effect as the relationship between mood and aggressiveness is also significant at the 5\% level. The results imply that the mechanism of mood induces the savings behaviours that are caused by the aggressiveness of the individual. Having a bad mood would increase the aggressiveness, and high aggressiveness would decrease the savings traits. In other words, aggressiveness occurs as an important mechanism explanation in governing the relationship between mood and savings traits. This is in line with previous research, such as Forgas (1989), Gul and Pesendorfer (2004), and Guven (2012).

\subsection{Moderating effect of the impulsive personality}

This study finds how the impulsive personality has failed to moderate the association between aggressiveness and savings behaviour in Indonesia and Malaysia, but not in Thailand and Vietnam. The relationship shows a negative sign in which the coefficients are $-0.731,-0.210,-0.244$, and -0.269 . However, unlike the results in Thailand and Vietnam, the t-values in Indonesia and Malaysia are lower than 1.96. The t-values are $0.143,0.272,2.259$, and 2.058 for the regression model in Indonesia, Malaysia, Thailand and Vietnam, respectively. It should be noted that a low value of interpersonal traits indicates an introvert personality and a high value of interpersonal traits indicates an extrovert personality.

Table 5 The moderating effects of Impulsivity

\begin{tabular}{|c|c|}
\hline & $O L S$ \\
\hline \multirow{3}{*}{ Indonesia } & -1.173 \\
\hline & $(0.143)$ \\
\hline & $\mathrm{n}=519$ \\
\hline \multirow{3}{*}{ Malaysia } & -0.21 \\
\hline & $(0.272)$ \\
\hline & $\mathrm{n}=566$ \\
\hline \multirow{3}{*}{ Thailand } & $-0.244 * *$ \\
\hline & $(2.259)$ \\
\hline & $\mathrm{n}=595$ \\
\hline \multirow{3}{*}{ Vietnam } & $-0.269 * *$ \\
\hline & $(2.058)$ \\
\hline & $\mathrm{n}=577$ \\
\hline $\mathrm{N}$ & 2,257 \\
\hline
\end{tabular}

Notes: The estimate model is run using cross-sectional data. $t$-value statistics are in parentheses, and above them is the coefficient value. $\mathrm{n}$ means the observation of sample. Meanwhile $\mathrm{N}$ is the total sample from four countries. *, **, and *** denotes $10 \%$ significance, $5 \%$ significance, and $1 \%$ significance, respectively. 
The findings show that personality plays a role as moderator in Thailand and Vietnam in the association between aggressiveness and savings. These estimations highlight two important points. Firstly, the aggressiveness of the individual in Indonesia and Malaysia has no interactive association effect with personality on the savings behaviour, thereby implying that it does not matter whether the individual is introvert or extrovert, it does not encourage them to make more savings. However, Thailand and Vietnam present a different picture for this relationship. The findings of personality as a moderating effect have been documented and have significant influences in these two countries indicating that different impulsive personalities have a different interaction effect with aggressiveness on the savings behaviour.

With regards to demography, the Indonesians and Malaysians have a similar culture, and share the same conclusion of moderating effect where there is a moderating effect of personality. Meanwhile, Thailand and Vietnam also have something in common regarding culture. But the moderating effect is found to be significant in these two countries. It seems that the aggressiveness role on savings behaviour has no interactive association with personality for 'Nusantara' descendants (Indonesia and Malaysia), but has effects for 'Indochina' descendants (Thailand and Vietnam). It does not matter whether they are introvert or extrovert, self-regulated or not, with high or low impulsivity, aggressiveness steadily influences the savings behaviour in Indonesia and Malaysia. Meanwhile, Thailand and Vietnam consider impulsive personality on the aggressiveness-savings link.

The conclusion about Nusantara and Indochina differences is supported by prior studies such as Bond et al. (2004) and Reisinger and Crotts (2009). For instance, Bond et al. (2004) surmise there are differences between nusantara and indochina in terms of dynamic and societal culture. They grouped Indonesia and Malaysia as a nation with cultures that are high in Dynamic Externality and low in Societal Cynicism. Meanwhile, Indochina culture such Thailand, are high in both dimensions. Note that dynamic externality culture means that the culture has close to cognitive component of social-system collectivism, a widely studied cultural complex assessed using other types of psychological constructs in other culture-level studies. Meanwhile, societal culture represents the cognitive component of an unrecognised cultural complex that might be labelled maleficence, reflecting the assessed hostility of the social system toward its members.

Reisinger and Crotts (2009) differentiate Indonesia, Malaysia, Thailand, and Vietnam by using Hofstede's culture measures. They surmise Indonesia and Malaysia have same behaviour as their cultural is invergent. Meanwhile, Indochina regions will have similar behaviour as their cultural is not divergent. In other words, Thais differ from Indonesians, but Indonesians is not much different from Malaysia. Furthermore, Reisinger and Crotts (2009) conclude that Indonesia and Malaysia have the same level of long-term commitment culture where these nations have similar level of persistence and patience.

Lastly, our study is in line with the World Value Survey where it documented in term of money orientation and consumption perception, Thailand and Vietnam can be clustered in one group, and Malaysia and Indonesia are clustered in another group. 


\subsection{Nusantara versus Indochina}

In the previous section, the findings documented how an impulsive personality fails to encourage less aggressive people to consume more in Thailand and Vietnam, but not in Indonesia and Malaysia. The different customs and culture between Nusantara (Indonesia and Malaysia) and Indochina (Thailand and Vietnam) might be the explanation for those differences (i.e., Bond et al., 2004; and Reisinger and Crotts, 2009). Therefore, we investigate further the differences by employing paired t-tests between the Indochina countries and Nusantara countries.

Table 6 shows that the mean difference between Indochina and Nusantara for impulsivity is 0.3623 , and the mean difference between Indochina and Nusantara for savings is 0.1396 . This implies that the impulsivity and savings between Nusantara and Indochina are different descriptively. Since the mean of impulsivity and savings of Indochina is greater than the mean for Nusantara's impulsivity and savings, we can conclude that Indochina has stronger associations of impulsivity and savings compared to Nusantara.

Table 6 Results of paired t-test

\begin{tabular}{lccc}
\hline & Mean differences & $t$-value & Sig. \\
\hline Impulsivity & 0.3622 & 2.053 & 0.0403 \\
Savings & 0.1396 & 1.738 & 0.0825 \\
\hline
\end{tabular}

Furthermore, the significant value of impulsivity differences in Table 6 is 0.0403 or less than 0.05 . This implies that there is a difference between Indochina's impulsivity and Nusantara's impulsivity at the significant level of $5 \%$. The t-value for the paired t-test between Indochina and Nusantara's savings is 1.738 . This means there is a significant difference between Indochina savings and Nusantara savings. Therefore, we can conclude that the savings behaviours between Indochina and Nusantara are significantly different. These findings explain why the aggressiveness-savings link in Indonesia and Malaysia (Nusantara) is different from the association found in Thailand and Vietnam (Indochina).

\section{Discussion}

Our findings surmise that the decision in favour of savings or consumption is very close to the mood of individuals. The results show that the higher the mood, the higher the savings traits. This relationship can be explained using the Mood-Induced Decision in behavioural economics. For instance, Finucane et al. (2000) stated that affection plays an important role in decision-making and guiding towards a judgement. The affection through mood influences the heuristic process and results in biased decision-making. In our case, the mood generates the heuristic bias decision and results in savings behaviour. However, if the mood induces aggressiveness, the individual tends to have more impulsive consumption rather than savings behaviour. 
Table 7 Estimations of structural equation model (PLS)

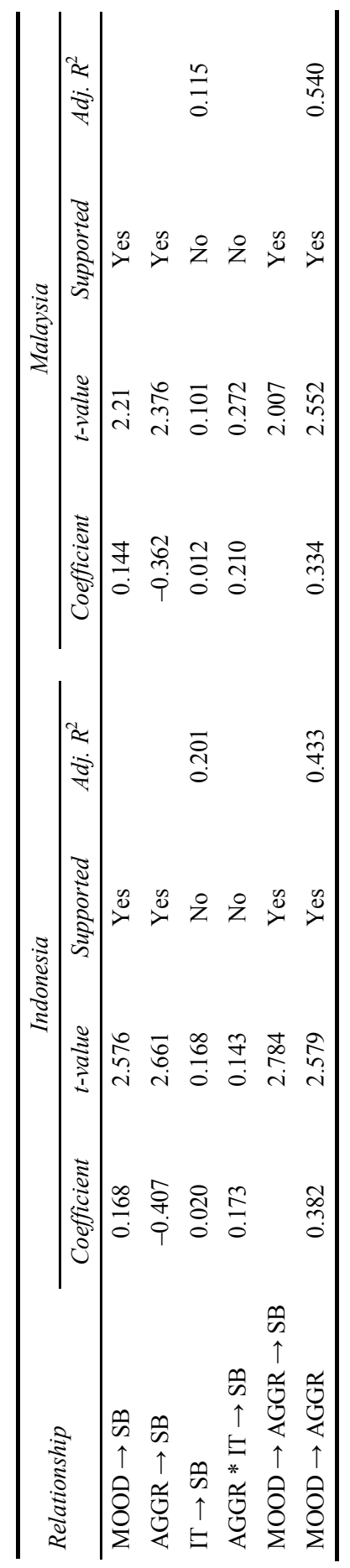


Table 7 Estimations of structural equation model (PLS)

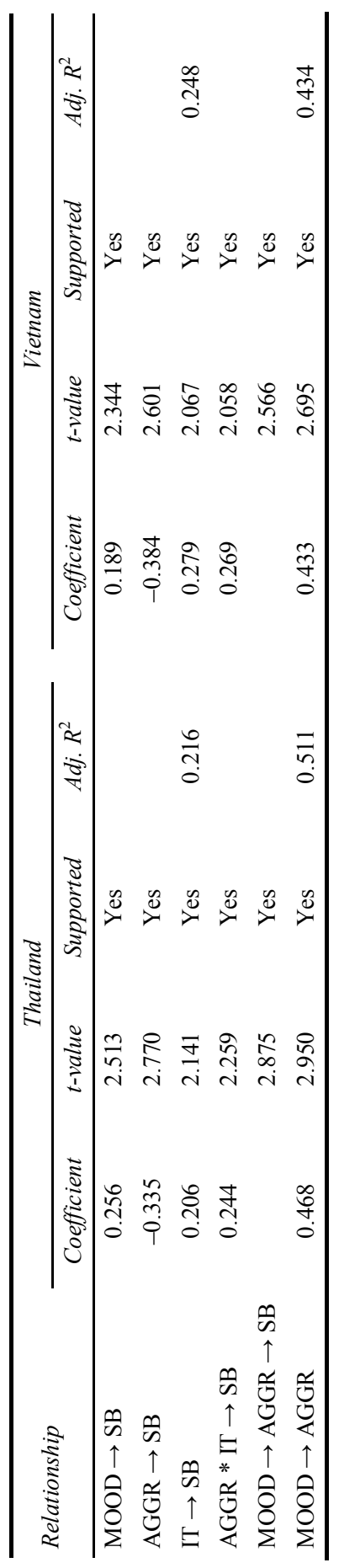


This relationship is also explicated by the previous classical work of Alice Isen.4 For instance, Isen and Means (1983) showed how mood affects the strategic decision-making. Just like our research, mood influences the savings behaviour because of the cognitive process. The mechanism proposed in this research is aggressiveness. Forgas (1989) explained how a positive mood and negative mood would influence the rational decision-making and level of awareness. In his model, he addressed the process of how mood is infused into a decision, which consists of

a decision time where a happy mood would make the individual take less time to decide

b decision efficiency where a happy mood would make the individual consider fewer irrelevant dimensions

c information preferences where a happy mood makes the individual search for more information before taking a decision; and, lastly

d information precession where a happy mood makes the individual think fast without any complexity.

Relating that back to our study, the happy mood of individuals would lead them to be more impulsive in consumption but less impulsive for savings. The decision time, decision efficiency, and information preferences are the reasoning behind this.

\section{Conclusions}

This paper attempts to answer whether the savings traits are induced by the mood and aggressiveness. This paper investigates the role of personality as a moderating variable. This means that the basic tenet of traditional economics, which is rational behaviour, is argued by proposing the hedonic utility. For reasons of robustness, the paper took four ASEAN countries and used the structural equation model to answer the research objectives.

The results are very interesting. Firstly, the savings behaviour of individuals was influenced by moods and the level of aggressiveness. The better the mood, the better the savings behaviour. The same conclusion also goes for the level of aggressiveness: the more aggressive an individual, the worse the savings behaviour. Secondly, the mood affects the aggressiveness of individuals leading to the savings behaviour. A good mood would produce low aggressiveness, and low aggressiveness would produce better savings behaviour. In short, aggressiveness would mediate the association between mood and savings behaviour.

Note that the survey in Indonesia and Malaysia shows how aggressiveness mediates the relationship between mood and savings behaviour. Meanwhile, the impulsive personality fails to induce the moderating effect for the relationship between aggressiveness and the savings behaviour. However, the survey in Thailand and Vietnam shows that after aggressiveness mediates the relationship between mood, and savings and behaviour, the personality has a moderating effect on the aggressiveness of savings behaviour. This implies that personality could not be taken into consideration in the savings behaviour of Malay descendants (Indonesia and Malaysia) but that it could for Indochina descendants (Thailand and Vietnam). To confirm the findings, this paper ran 
paired t-tests to determine whether there are differences in savings behaviour in four ASEAN countries. The result is a tally in which there are significant differences between Nusantara descendants and Indochina descendants.

In conclusion, the savings traits of four ASEAN countries were determined and differentiated by the psychological characteristics of individuals. Regulators can use the findings by controlling inflation through monetary policy following the mood cycle of individuals. The findings can also be used for policymaking. For instance, understanding the link between mood, aggressiveness, personality, and savings behaviour can help design tax and retirement policies. It can also help regulate the timing of macroeconomic announcements (announcements of unemployment, inflation, tax level, increases in wages and salary, increases in commodity prices). Future research may tackle this issue by examining whether macroeconomic news would cause more inflation or other seasonality because of moods. Future research can also extend this study by adding the source of mood attribution, such as happiness, sunshine, moon gravity, and other mood attributions.

\section{References}

Baron, R.M. and Kenny, D.A. (1986) 'The moderator-mediator variable distinction in social psychological research: conceptual, strategic and statistical considerations', Journal Personality Social Psychology, Vol. 51, No. 6, pp.1173-1182.

Beja, E.L. Jr. (2012) What Do Happy People Choose: Rapid Economic Growth or Stable Economy?, Unpublished MPRA paper.

Biel, A., Johansson-Stenman, O. and Nilsson, A. (2011) 'The willingness to pay-willingness to accept gap revisited: the role of emotions and moral satisfaction', Journal of Economic Psychology, Vol. 32, No. 6, pp.908-917.

Bond, M.H., Leung, K., Au, A., Tong, K.K., De Carrasquel, S.R., Murakami, F. and Sam, D.L. (2004) 'Culture-level dimensions of social axioms and their correlates across 41 cultures', Journal of Cross-Cultural Psychology, Vol. 35, No. 5, pp.548-570.

Borsch-Supan, A. and Stahl, K. (1991) 'Do savings programs dedicated to home-ownership increase personal savings? An analysis of the West German Bausparkassen system', Journal of Public Economics, Vol. 44, No. 3, pp.265-297.

Brahmana, R., Hooy, C.W. and Ahmad, Z. (2012) 'Psychological factors on irrational financial decision making: case of day-of-the week anomaly', Humanomics, Vol. 28, No. 4, pp.236-257.

Brandstatter, H. (1993) 'Should economic psychology care about personality structure', Journal of Economic Psychology, Vol. 14, No. 3, pp.473-494.

Camerer, C.F. (2011) 'Psychological influences on economic choice: Pavlovian cuing and emotional regulation', in Delgado, M.R., Phelps, E.A. and Robbins, T.W. (Eds.): Decision Making, Affect, and Learning: Attention and Performance, Oxford University Press, Oxford.

Caplin, A. and Leahy, J. (2001) 'Psychological expected utility theory and anticipatory feelings', The Quarterly Journal of Economics, Vol. 116, No. 1, pp.55-79, doi:10.1162/ 003355301556347

Carlson, R., Lohse-Busch, H., Duoba, M. and Shidore, N. (2009) Drive Cycle Fuel Consumption Variability of Plug-In Hybrid Electric Vehicles Due to Aggressive Driving, SAE Technical Paper 2009-01-1335, doi:10.4271/2009-01-1335.

Cella, D.F., Jacobsen, P.B., Orav, E.J., Holland, J.C., Silberfarb, P.M. and Rafla, S. (1987) 'A brief POMS measure of distress for cancer patients', Journal of Chronic Diseases, Vol. 40, No. 10, pp.939-942. 
Davis, R., Freeman, R. and Solyom, L. (1985) 'Mood and food: an analysis of bulimic episodes', Journal of Psychiatric Research, Vol. 19, Nos. 2-3, pp.331-335.

Dodge, K.A. and Newman, J.P. (1981) 'Biased decision-making processes in aggressive boys', Journal of Abnormal Psychology, Vol. 90, No. 4, pp.375-379, doi:10.1037/ 0021-843X.90.4.375.

Donnelly, G., Iyer, R. and Howell, R.T. (2012) 'The Big Five personality traits, material values, and financial well-being of self-described money managers', Journal of Economic Psychology, Vol. 33, No. 6, pp.1129-1142.

Epstein, L.G. and Zin, S.E. (1989) 'Substitution, risk aversion, and the temporal behavior of consumption and asset returns: a theoretical framework', Econometrica, Vol. 57, No. 4, pp.937-969.

Eysenck, H.J. and Eysenck, S.B.G. (1975) Manual of the Eysenck Personality Questionnaire, Hodder and Stoughton, London.

Finucane, M.L., Alhakam, A.S., Slovic, P. and Johnson, S.M. (2000) 'The affect heuristic in judgement of risk and benefits', Journal of Behavioural Decision Making, Vol. 13, No. 1, pp.1-17.

Forgas, J.P. (1989) 'Mood effects on decision making strategies', Australian Journal of Psychology, Vol. 41, No. 2, pp.197-214, doi:10.1080/00049538908260083.

Frank, R.H. and Hutchens, R.M. (1993) 'Wages, seniority, and the demand for rising consumption profiles', Journal of Economic Behaviour and Organization, Vol. 21, No. 3, pp.251-276.

Ghosh, A. and Ostry, J.D. (1997) 'Macroeconomic uncertainty, precautionary saving, and the recurrent account', Journal of Monetary Economics, Vol. 40, No. 1, pp.121-139.

Gul, F. and Pesendorfer, W. (2004) 'Self-control and the theory of consumption', Econometrica, Vol. 72, No. 1, pp.119-158, doi:10.1111/j.1468-0262.2004.00480.x.

Guven, C. (2012) 'Reversing the question: does happiness affect consumption and savings behavior?', Journal of Economic Psychology, Vol. 33, No. 4, pp.701-717.

Hair, J.F., Black, W.C., Babin, B.J. and Anderson, R.E. (2010) Multivariate Data Analysis, Prentice-Hall, Upper Saddle River.

Harle, K.M., Chang, L.J., Van Wout, M. and Sanfey, A.G. (2012) 'The neural mechanisms of affect infusion in social economic decision-making: a mediating role of the anterior insula', NeuroImage, Vol. 61, No. 1, pp.32-40.

Harrison, N. and Chudry, F. (2011) 'Overactive, overwrought or overdrawn? The role of personality in undergraduate financial knowledge, decision-making and debt', Journal of Further and Higher Education, Vol. 35, No. 2, pp.149-182, doi:10.1080/ 0309877X.2010.540080.

Iscan, T. (2011) 'Productivity growth and the US saving rate', Economic Modelling, Vol. 28, Nos. 1-2, pp.501-514.

Isen, A.M. and Means, B. (1983) 'The influence of positive affect on decision making strategy', Social Cognition, Vol. 2, No. 1, pp.18-31.

Isen, A.M. and Simmonds, S.F. (1978) 'The effect of feeling good on a helping task that is incompatible with good mood', Social Psychology, Vol. 41, No. 4, pp.346-349.

Janis, I.L. and Mann, L. (1977) Decision Making: A Psychological Analysis of Conflict, Choice, and Commitment, Free Press, New York.

Johnson, S.K., Tulsky, J.A., Hays, J.C., Arnold, R.M., Olsen, M.K., Lindquist, J.H. and Steinhauser, K.E. (2012) 'Which domains of spirituality are associated with anxiety and depression in patients with advanced illness?', Journal of General Internal Medicine, Vol. 26, No. 7, pp.751-758, doi:10.1007/s11606-011-1656-2.

Kahneman, D. and Tversky, A. (1974) 'Subjective probability: a judgment of representativeness', The Concept of Probability in Psychological Experiments, pp.25-48, Springer, Netherlands.

Kahneman, D., Diener, E. and Schwarz, N. (Eds.) (1999) Well-Being: Foundations of Hedonic Psychology, Russell Sage Foundation, New York. 
Kassarjian, H.H. (1971) 'Personality and consumer behavior: a review', Journal of Marketing Research, Vol. 8, No. 4, pp.409-418.

Keller, M.C., Fredrickson, B.L., Ybarra, O., Cote, S., Johnson, K., Mikels, J., Conway, A. and Wager T. (2005) 'The contingent effects of weather on mood and cognition', Psychological Science, Vol. 16, No. 9, pp.724-731, doi:10.1111/j.1467-9280.2005.01602.x.

Kleider, H.M. and Parrott, D.J. (2009) 'Aggressive shooting behavior: how working memory and threat influence shoot decisions', Journal of Research in Personality, Vol. 43, No. 3, pp.494-497.

Koenigs, M. and Tranel, D. (2007) 'Irrational economic decision-making after ventromedial prefrontal damage: evidence from the ultimatum game', The Journal of Neuroscience, Vol. 27, No. 4, pp.951-956.

Lunt, P.K. (1991) 'Psychological, social and economic determinants of saving: comparing recurrent and total savings', Journal of Economic Psychology, Vol. 12, No. 4, pp.621-641.

Mann, L. (1992) 'Stress, affect, and risk taking', in J.F. Yates (Ed.): Risk Taking Behaviour, Wiley, Michigan.

Mehrabian, A. and Riccioni, M. (1986) 'Measures of eating-related characteristics for the general population: relationships with temperament', Journal of Personality Assessment, Vol. 50, No. 4, pp.610-629, doi:10.1207/s15327752jpa5004_8.

Moutoussis, M. (2011) 'Homicide rates and income inequality', The British Journal of Psychiatry, Vol. 199, No. 4, pp.341-341.

Rabin, M. (1998) 'Psychology and economics', Journal of Economic Literature, Vol. 36, No. 1, p.11.

Reisinger, Y. and Crotts, J.C. (2009) 'Applying Hofstede's national culture measures in tourism research: illuminating issues of divergence and convergence', Journal of Travel Research, Vol. 49, No. 2, pp.153-164.

Retiveau, A.N., Chambers, E. and Milliken, G.A. (2004) 'Common and specific effects of fine fragrances on the mood of women', Journal of Sensory Studies, Vol. 19, No. 5, pp.373-394.

Sandmo, A. (1969) 'Capital risk, consumption, and portfolio choice', Econometrica, Vol. 37, No. 4, pp.586-599.

Seaver, W.B. and Patterson, A.H. (1976) 'Decreasing fuel-oil consumption through feedback and social commendation', Journal of Applied Behavioural Analysis, Vol. 9, No. 2, pp.147-152, doi:10.1901/jaba.1976.9-147.

Shoham, A. and Malul, M. (2012) 'The role of cultural attributes in savings rates', Cross Cultural Management: An International Journal, Vol. 19, No. 3, pp.304-314.

Stein, C.H., Hoffmann, E., Bonar, E.E., Leith, J.E., Abraham, K.M., Hamill, A.C., Kraus, S.W., Gumber, S. and Fogo, W.R. (2012) 'The United States economic crisis: young adults' reports of economic pressures, financial and religious coping and psychological well-being', Journal of Family and Economic Issues, Vol. 34, No. 2, pp.200-210.

Steinhauser, K.E., Arnold, R.M., Olsen, M.K., Lindquist, J., Hays, J., Wood, L.L., Burton, A.M., and Tulsky, J.A. (2011) 'Comparing three life-limiting diseases: does diagnosis matter or is sick, sick?', Journal of Pain and Symptom Management, Vol. 42, No. 3, pp.331-341.

Steptoe, A. and Wardle, J. (1999) 'Mood and drinking: a naturalistic diary study of alcohol, coffee and tea', Psychopharmacology, Vol. 141, No. 3, pp.315-321, doi:10.1007/s002130050839.

Stillman, T.F., Fincham, F.D., Vohs, K.D., Lambert, N.M. and Phillips, C.A. (2012) 'The material and immaterial in conflict: spirituality reduces conspicuous consumption', Journal of Economic Psychology, Vol. 33, No. 1, pp.1-7.

Strack, F., Werth, L. and Deutsch, R. (2006) 'Reflective and impulsive determinants of consumer behavior', Journal of Consumer Psychology, Vol. 16, No. 3, pp.205-216.

Tangari, A.H. and Smith, R.J. (2012) 'How the temporal framing of energy savings influences consumer product evaluations and choice', Psychology and Marketing, Vol. 29, No. 4, pp.198-208. 
Tvede, L. (2002) The Psychology of Finance: Revised Edition, John Wiley and Son, New York.

Van der Zwaag, M.D., Dijksterhuis, C., de Waard, D., Mulder, B.L., Westerink, J.H. and Brookhuis, K.A. (2012) 'The influence of music on mood and performance while driving', Ergonomics, Vol. 55, No. 1, pp.12-22.

Van Winden, F., Krawczyk, M. and Hopfensitz, A. (2011) 'Investment, resolution of risk, and the role of affect', Journal of Economic Psychology, Vol. 32, No. 6, pp.918-939.

Vollrath, M. and Torgersen, S. (2002) 'Who takes health risks? A probe into eight personality types', Personality and Individual Differences, Vol. 32, No. 7, pp.1185-1197.

Wahhaj, Z. (2010) 'Social norms and individual savings in the context of informal insurance', Journal of Economic Behavior and Organization, Vol. 76, No. 3, pp.511-530.

Whiteside, S.P. and Lynam, D.R. (2001) 'The five factor model and impulsivity: using a structural model of personality to understand impulsivity', Personality and Individual Differences, Vol. 30, No. 4, pp.669-689.

\section{Notes}

1 See Eysenck and Eysenck (1975) for the detailed explanation of the personality traits inventory.

2 Guven (2012) addressed this as a limitation of the study.

3 The tables can be provided upon request.

4 Psychology Marketing scholar from the University of Cornell who is famous for her papers about moods and decision-making.

\section{Appendix}

1 The questionnaires were translated using professional translators located in Indonesia (Surabaya), Malaysia (Penang), Thailand (Bangkok), and Vietnam (Ho Chi Minh). It was back-to-back translation in which one translator translated from English to the local language, and then another translator translated back from the local language to English. For reasons of robustness, the translated questionnaire was pre-tested by distributing to students (Indonesia's and Malaysia's Questionnaire) and through focus group discussion with faculty members of schools of social science and schools of literacy (conducted in all countries).

2 The mediation effect was tested using the following formula.

$$
t=\frac{a \times b}{\sqrt{b^{2} \times S_{a}^{2}+a^{2} \times S_{b}^{2}+S_{a}^{2} \times S_{b}^{2}}},
$$

where ' $a$ ' is the path coefficients from mood to aggressiveness ' $b$ ' is the path coefficients from aggressiveness to savings behaviour; ' $S_{a}$ ' is the standard deviation from mood to aggressiveness; ' $S_{b}$ ' is the standard deviation from aggressiveness to savings behaviour. 
3 Even though the partial least squares is a non-parametric test that does not need a huge sample, the rule of sample size is the number of relationship arrows going to a dimension/variable times 10 (see Hair et al., 2010). This research has five relationship arrows going to dimensions/variables (see equation (3) and we know there are five predictors], hence the sample size needed is 5 times 10 , which is 50 samples per country. In short, our sample by country is suitable for use in the model. 